Neuroepidemiology 2014;43:269-271

DOI: $10.1159 / 000368308$

\section{Trends in Inpatient Mortality After Ischemic and Hemorrhagic Strokes in the United States}

Yogesh Moradiya a, Santosh B. Murthy ${ }^{\mathrm{a}}$, Christa O'Hana V. San Luis ${ }^{\mathrm{a}}$, Sneha Modi ${ }^{\mathrm{b}}$, Neeraj Naval ${ }^{\mathrm{a}}$

${ }^{a}$ Division of Neurosciences Critical Care, Johns Hopkins School of Medicine and ${ }^{b}$ Department of Medicine, MedStar Franklin Square Medical Center, Baltimore, Md., USA

We studied the trends in inpatient mortality after acute ischemic stroke (AIS), intracerebral hemorrhage (ICH), and subarachnoid hemorrhage (SAH) in the United States in a retrospective cross-sectional study from 2002 to 2011.

\section{Methods}

Data Source. We analyzed the Nationwide Inpatient Sample (NIS) of Healthcare Cost and Utilization Project (HCUP), the largest all-payer inpatient database in the United States consisting of $20 \%$ of all admissions in nonfederal hospitals. Detailed information regarding NIS is available at the HCUP website [1].

Case-Selection. We used validated International Classification of Diseases, Ninth Revision, Clinical Modification (ICD-9$\mathrm{CM}$ ) codes to identify adults (age $\geq 18$ years) with primary diagnosis of AIS (433.x1, 434.x1, and 436), ICH (431) and SAH (430) [2]. Transferred patients were excluded to prevent double counting.

Severity Adjustment. $3 \mathrm{M}^{\mathrm{TM}}$ all patient refined diagnosis-related groups (APR-DRGs)-based risk of mortality subclass, a validated proprietary risk-adjustment algorithm [3], and Charlson comorbidity index [4] were used for case severity adjustment.

Statistical Analysis. Mortality rates are presented as percent proportion and standard error of population estimates obtained by using sample weighting and adjusted for clustering and stratification of NIS design [5]. Multivariate-adjusted trends in inpatient

Fig. 1. Temporal trends in crude mortality rates and multivariate-adjusted relative mortality risk differences after ischemic and hemorrhagic strokes in the United States between 2002 and 2011. a-c Trends in crude inpatient mortality as percent proportion of all cases treated. $p$ value $<0.001$ for all 3 linear trends across time. d Trends in multivariate-adjusted relative mortality risk difference after AIS, ICH and SAH as calculated by the negative binomial regression-derived risk ratios multiplied by mortality rate mortality were calculated by negative binomial regression using unweighted counts to obtain risk ratios. SPSS version 21 was used for analyses.

\section{Results}

We analyzed 3,659,076 AIS (crude mortality rate \pm SE, $5.6 \pm$ $0.1 \%), 622,844 \mathrm{ICH}(29.3 \pm 0.2 \%)$, and $232,283 \mathrm{SAH}(25.2 \pm 0.4 \%)$ cases. Unadjusted mortality decreased from 2002 to 2011 for all stroke types (AIS: $6.6 \pm 0.1 \%$ to $4.5 \pm 0.1 \%$, ICH: $32.7 \pm 0.5 \%$ to $25.6 \pm 0.5 \%$, and SAH: $31.5 \pm 0.8 \%$ to $21.5 \pm 0.9 \%$, respectively, $\mathrm{p}<0.001$ for all 3 trends) (fig. $1 \mathrm{a}-\mathrm{c}$ ). Adjusted mortality risk ratios with each year increment were 0.927 (95\% confidence interval: 0.924-0.929) for AIS, $0.948(0.945-0.951)$ for ICH, and 0.948 (0.943-0.953) for SAH (fig. 1d).

\section{Comment}

Recent studies of trends in stroke mortality in the United States are limited by inclusion of selective nonrepresentative populations with limited generalizability $[6,7]$. We studied stroke mortality trends from a nationally representative sample and found that adjusted relative mortality in recent years has decreased in adults with primary diagnosis of AIS by 7.3\% (95\% confidence interval: 7.1-7.6\%), ICH by $5.2 \%(4.9-5.5 \%)$, and SAH by $5.2 \%(4.7-5.7 \%)$ annually in the United States. This represents ongoing improvements in the management of ischemic and hemorrhagic strokes [8]. We hypothesize that quality improvement programs such as Get With The Guidelines, stroke center certification programs, and recent expansion of neurocritical care resources and workforce across the country may have influenced the mortality $[9,10]$; however, causality is not proven in this study. Additionally, more frequent diagnosis of milder strokes during recent times may have contributed to the change in mortality.

Limitations include the use of administrative data and lack of stroke-specific severity measures. Coding errors are possible, however; ICD-9-CM codes used in the study have high accuracy [2] and random coding errors would bias the results toward null so the differences found are likely to be valid.

In summary, ischemic and hemorrhagic stroke-related inpatient mortality is declining in the United States and the continuing downward linear trends suggest that the mortality may continue to decline before it plateaus. in 2002 as reference. Factors included in the model are age, sex, race, hospital bedsize, region, location, teaching status, Charlson comorbidity index, and all patient-refined, diagnosis-related groups risk of mortality subclass. $p$ value $<0.001$ for all 3 linear trends across time. Error bars indicate $95 \%$ confidence intervals. AIS = Acute ischemic stroke; $\mathrm{ICH}=$ intracerebral hemorrhage; $\mathrm{SAH}=$ subarachnoid hemorrhage.

(For figure see next page.)

\section{KARGER}

E-Mail karger@karger.com

www.karger.com/ned
2014 S. Karger AG, Basel

$0251-5350 / 14 / 0434-0269 \$ 39.50 / 0$
Yogesh Moradiya, MD

Division of Neurosciences Critical Care, Johns Hopkins School of Medicine 600 N Wolfe Street, Phipps 455 Baltimore, MD 21287-7840 (USA)

E-Mail YogeshMoradiyaMD@Gmail.com 
AIS

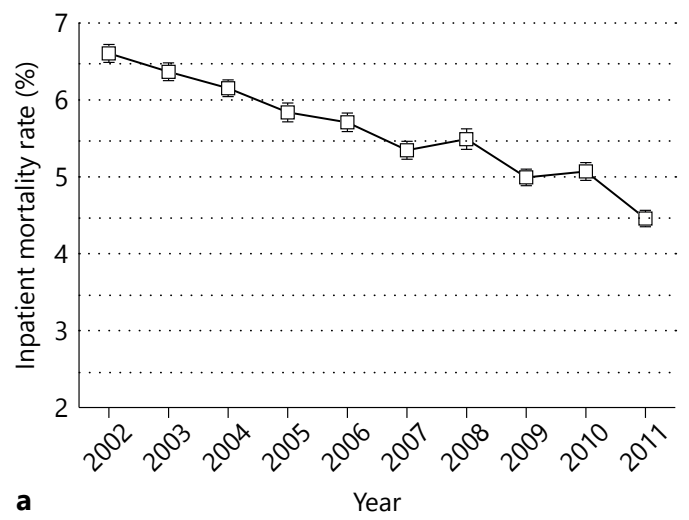

SAH

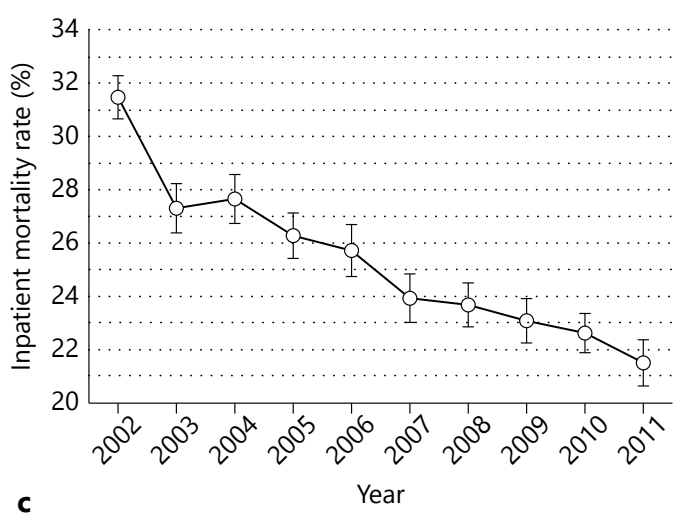

$\mathrm{ICH}$

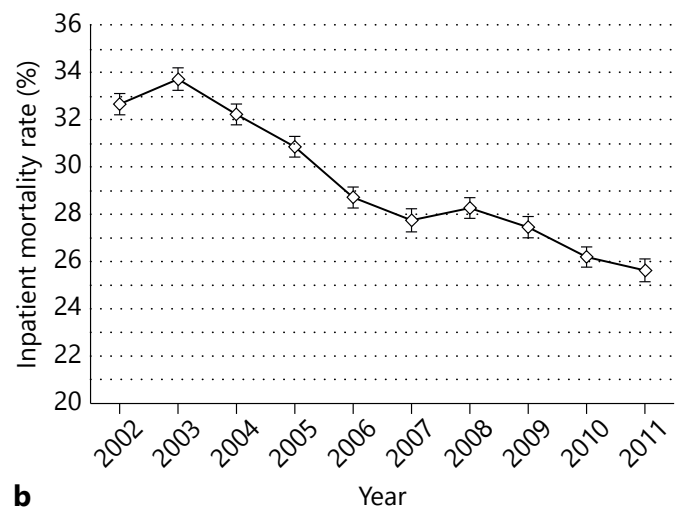

Adjusted mortality trends

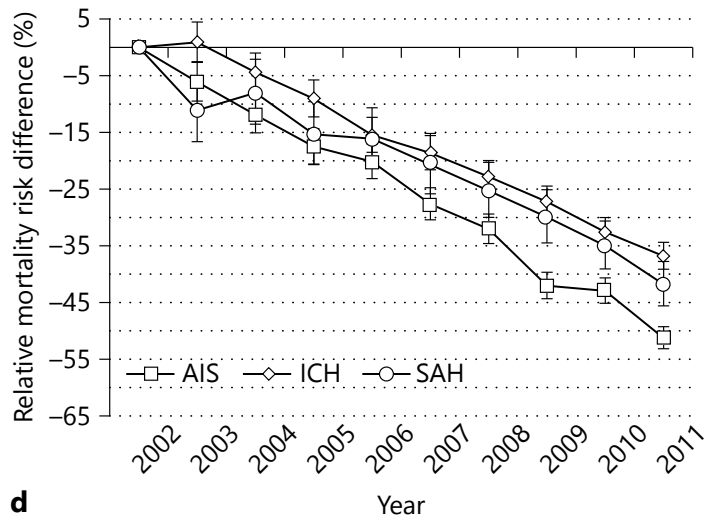

\section{Acknowledgment}

Dr. Moradiya had full access to all of the data in the study and takes responsibility for the integrity of the data and the accuracy of the data analysis.

\section{Author Contributions}

Study concept and design: Moradiya, Modi.

Acquisition, analysis, or interpretation of data: Moradiya, Murthy.

\section{References}

1 Overview of the Nationwide Inpatient Sample (NIS): Healthcare Cost and Utilization Project (HCUP). Agency for Healthcare Research and Quality, Rockville, MD. www.hcup-us.ahrq.gov/nisoverview.jsp (accessed July 1, 2014).

2 Kokotailo RA, Hill MD: Coding of stroke and stroke risk factors using international classification of diseases, revisions 9 and 10. Stroke 2005; 36:1776-1781.

3 All Patient Refined Diagnosis Related Groups (APR-DRGs) Version 20.0 Methodology Overview: 3M Health Information Systems. http://www. hcup-us.ahrq.gov/db/nation/nis/APR-DRGsV20MethodologyOver viewandBibliography.pdf (accessed July 1, 2014).
Drafting of the manuscript: Moradiya.

Critical revision of the manuscript for important intellectual content: Moradiya, Murthy, San Luis, Modi, Naval.

Statistical analysis: Moradiya.

Study supervision: Naval.

\section{Disclosure Statement}

None. 
6 Fang MC, Perraillon MC, Ghosh K, Cutler DM, Rosen AB: Trends in stroke rates, risk, and outcomes in the United States, 1988-2008. Am J Med 2014;127:608-615.

7 Zahuranec DB, Lisabeth LD, Sanchez BN, Smith MA, Brown DL, Garcia NM, Skolarus LE, Meurer WJ, Burke JF, Adelman EE, et al: Intracerebral hemorrhage mortality is not changing despite declining incidence. Neurology 2014;82:2180-2186.

8 Schwamm LH, Fonarow GC, Reeves MJ, Pan W, Frankel MR, Smith EE, Ellrodt G, Cannon CP, Liang L, Peterson E, et al: Get With the Guidelines-Stroke is associated with sustained improvement in care for patients hospitalized with acute stroke or transient ischemic attack. Circulation 2009;119:107-115.
99 Fonarow GC, Zhao X, Smith EE, Saver JL, Reeves MJ, Bhatt DL, Xian Y, Hernandez AF, Peterson ED, Schwamm LH: Door-to-needle times for tissue plasminogen activator administration and clinical outcomes in acute ischemic stroke before and after a quality improvement initiative. JAMA 2014;311:1632-1640.

10 Lichtman JH, Jones SB, Leifheit-Limson EC, Wang Y, Goldstein LB: 30day mortality and readmission after hemorrhagic stroke among Medicare beneficiaries in Joint Commission primary stroke center-certified and noncertified hospitals. Stroke 2011;42:3387-3391. 